\title{
Da hegemonia aos estereótipos do ser professor: os enlaces do preconceito no cotidiano formativo
}

\author{
From hegemony to stereotypes of being a teacher: the links of prejudice in the formative everyday
}

life

De la hegemonía a los estereótipos del ser docente: los eslabones del prejuicio em la formación cotidiana

\section{Resumo}

O presente estudo traz como objetivo apresentar o levantamento acerca da produção do conhecimento a partir da lei 10.639/03 e sua efetividade na prática formativa. Caracterizada como uma pesquisa do tipo qualitativa, considerou-se para coleta os seguintes bancos de dados: Portal de Periódicos Capes, Scielo, Lilacs e Biblioteca Digital Brasileira de Teses e Dissertações. Como descritores adotou-se os termos "formação de professores", "relações étnico raciais", "étnico racial”, “formação", "Lei 10.639/03” e "educação física”, associando o operador booleano "AND” entre os termos. Os dados coletados, resultaram em 153 produções científicas. Após averiguação das pesquisas adotando critérios de seleção, resultaram na especificidade de 02 que representavam as propositivas delimitadas. Sustentando na premissa da análise de conteúdos, os resultados indicaram a escassez da produção científica sobre a temática das relações étnico raciais no processo de formação inicial em Educação Física, evidenciando as incongruências entre a legalidade, e a efetividade de implementação de uma política curricular legitimida no campo da prática formativa. Os dados apresentados reiteram a necessidade de uma aplicação na clareza acerca dos constructos formativos como potenciais agentes influenciadores nos rabiscos iniciais da identidade dos futuros professores, a partir da celeridade da efetiva inclusão do respeito e da valorização da diversidade étnico racial.

Palavras-chave: Formação de professores; Relações étnico-raciais; Educação física; Ensino.

\begin{abstract}
This study aims to present the survey about the production of knowledge from the Law 10.639/03 and its effectiveness in formative practice. Characterized as qualitative research, it was considered the following databases for the collection: Portal de Periódicos Capes, Scielo, Lilacs and Brazilian Digital Library of Theses and Dissertations. As descriptors was adopted the terms "teacher training", "ethno-racial relations", "ethno-racial", "training", "Law 10.639/03" and "physical education", associating the Boolean operator "AND" between the terms. The data collected resulted in 153 scientific productions. After verifying the researches by adopting a selection criteria, they resulted in 02 articles that represented the delimited propositions. Supported by the premise of content
\end{abstract}


analysis, the results indicated the scarcity of scientific production on the theme of ethnic and racial relations in the process of initial formation in Physical Education, showing the inconsistencies between the legality and effectiveness of implementing a curricular policy legitimized in the field of initial formation. The data presented reiterate the need for an expansion in the clarity about the formative constructs as potential influential agents in the initial drafts of the identity of future teachers, from the speed of the effective inclusion of respect and appreciation of ethnic and racial diversity.

Keywords: Teacher training; Ethnic-racial relations; Physical education; Teaching.

\section{Resumen}

El presente estudio tiene como objetivo presentar el levantamiento sobre la producción de conocimiento a partir de la ley 10.639/03 y su eficacia en la práctica formativa. Caracterizada como una investigación cualitativa, las siguientes bases de datos fueron consideradas para la colección: Portal de Periódicos Capes, Scielo, Lilacs y Biblioteca Digital Brasileña de Tesis y Disertaciones. Como descriptores, fueron adoptados los términos "formación docente", "relaciones étnico-raciales", “etnia racial”, “formación”, “Ley 10.639/03” y “educación física”, asociando el operador booleano "Y" entre los términos. Los datos recopilados dieron como resultado 153 producciones científicas. Después de la investigación de las investigaciones que adoptaron criterios de selección, resultó la especificidad de 02 que representó las proposiciones delimitadas. Con base en la premisa del análisis de contenido, los resultados indicaron la escasez de producción científica sobre el tema de las relaciones étnico-raciales en el proceso de formación inicial en Educación Física, destacando las inconsistencias entre la legalidad y la efectividad de implementar una política curricular legitimada en el campo de la práctica formativa. Los datos presentados reiteran la necesidad de aumentar la claridad sobre los constructos formativos como potenciales agentes influyentes en los esbozos iniciales de la identidad de los futuros docentes, a partir de la velocidad de inclusión efectiva del respeto y valoración de la diversidad étnica racial.

Palabras clave: Formacíon de professores; Relaciones étnico-raciales; Educacíon física; Enseñanza.

\section{Introdução}

A formação inicial de professores como um processo, para além da profissionalização dos docentes que atuarão com as novas gerações no/do cenário escolar (Garcia, 2005), configura-se na efetividade da formação de um profissional da educação que traz em sua biografia identitária o ser professor enquanto um agente que possibilita a mediação, a reflexão e a busca por uma sociedade mais humana e plural, conduzida sob a égide da diversidade, respeito às diferenças culturais e socioeconômicas, buscando romper com os estereótipos de uma sociedade hegemônica sustentada pelo discurso da meritocracia (Da Costa Borim, 2020).

Considerando o processo de formação de professores de Educação Física junto aos documentos norteadores, a saber: Diretrizes Curriculares Nacionais dos Cursos de Graduação em Educação Física, Diretrizes Curriculares Nacionais para formação inicial em nível superior, Diretrizes Curriculares Nacionais para a Formação Inicial de Professores para Educação Básica, Base Nacional Comum para a Formação Inicial de Professores, surge a seguinte indagação: qual a consequência da improficuidade do respeito e valorização da diversidade étnico racial na formação de futuros professores dessa área de conhecimento e intervenção?

Assume-se a compreensão de que a formação inicial em Educação Física se configura como uma etapa fundamental de reflexão e autorreflexão do processo de constituição da identidade do futuro professor, por meio de disciplinas, estágios, práticas e atividades extracurriculares que o aproxima da realidade escolar (Flores, 2018). Desde o seu ingresso na universidade, nota-se que uma representação da docência se apresenta dentro da percepção dos licenciandos em Educação Física, a qual emerge do olhar de antigo aluno. Nesse sentido, durante sua trajetória na graduação, faz-se necessário que as ações formativas busquem romper com os estereótipos e arquétipos trazidos dos contextos por vezes arcaicos dos modelos escolares, na tentativa de ressaltar olhares para a diversidade e respeito ao multiculturalismo e a humanização da sociedade (Anversa et al., 2020; Costa et al. 2020).

Para tanto, o presente estudo, caracterizado como uma pesquisa do tipo qualitativa, revisão integrativa, se propõe refletir acerca do silenciamento durante essa formação inicial das questões étnico raciais, ao trazer para o debate a produção científica sobre tal articulação. Traçou-se como objetivo apresentar o levantamento acerca da produção do conhecimento a 
partir da lei 10.639/03 e a sua efetividade na prática formativa.

\subsection{Formação inicial em Educação Física: reflexões iniciais}

Trazer a cena reflexões acerca do processo formativa de professores, implica ressaltar as tratativas estruturais que configuram a organicidade da estruturação da matriz curricular do curso de formação inicial. Tomando por base essa prerrogativa evidencia-se a necessidade do romper com a linearidade da burocratização do processo efetivo de implementação das estruturas formativas alicerçadas em saberes e competências meramente profissionais, ampliando o acesso formativo para que o futuro professor/a perceba em sua biografia as relações entre o ser e estar na profissão (Lima Monteiro 2020; Ramalho et al. 2021). Considera-se no processo de formação do professor ações que possibilitem a formação humana, na qual as ações didático-pedagógica, o campo investigativo, educativo, dos conhecimentos e habilidades possibilitem o desenvolvimento profissional tendo a sensibilidade para com o processo de co-responsabilização com a sociedade (Silva Junior et al., 2019; Silva, Almeida, Dias 2020).

Para tanto, as observâncias em destaque na pesquisa, partem da efetividade legal do processo formativo, instituída pelas Diretrizes Curriculares Nacionais, no caso específico da pesquisa, dos Cursos de Graduação em Educação Física, para que em âmbito nacional a profissão tenha uma qualificação equivalente, respeitando ao mesmo momento suas particularidades regionais. Segundo essas Diretrizes a Educação Física (Brasil, 2018a) se caracteriza uma área do conhecimento que se dedica a estudar o movimento humano, cultura corporal do movimento nas diferentes modalidades da ginástica, do jogo, do esporte, das lutas e da dança, garantindo de maneira plural as questões sociais no campo da saúde, da educação e da formação, da cultura, do esporte de alto rendimento e do lazer.

Nota-se que os cursos estão passando por uma reformulação, condicionando os futuros professores a uma etapa comum, na qual dentre os conhecimentos estabelecidos temos os "socioculturais do ser humano" (Brasil, 2018a). Nessa direção, ainda que de maneira inicial, os estudantes caminham para alcançar um entendimento com consciência e sensibilidade social, percebendo que o corpo estudado se mostra plural à cultura do movimento corporal.

No caso, da especificidade discutida na pesquisa, e por se tratar da formação de professores, as discussões centram-se, neste momento na formação específica em licenciatura em Educação Física. A partir disso, tal documento norteador nos apresenta que a formação em licenciatura deve considerar, entre vários aspectos, o respeito e a valorização da diversidade étnico racial, para que a educação seja igualitária, evidenciando o acesso e a permanência nas condições de melhoria e democratização de ensino (Brasil, 2018a).

Ao pontuar sobre o respeito e valorização da diversidade étnico racial interpretamos que a sociedade em sua estruturação não se faz “justa, equânime e igualitária” (Brasil, 2015; Brasil, 2019) como nos aponta a idealização das Diretrizes para a formação inicial em nível superior. Entendendo o ambiente das faculdades e universidades como principais para a formação inicial devemos considerar que os indivíduos que a compõe são educados por "processos formativos que se desenvolvem na vida familiar, na convivência humana, no trabalho, [...] nos movimentos sociais e organizações da sociedade civil [...]" (Brasil, 2015, p.4).

Nessa direção, destaca-se que toda a composição mencionada acima reflete as formas sociais que se materializam nas instituições. Hirsch (1990) acentua que "instituições são modos de orientação, rotinização e coordenação de comportamentos que tanto orientam a ação social como a tornam normalmente possível, proporcionando relativa estabilidade aos sistemas sociais". Tal estabilidade mencionada do sistema social decorre da dependência das instituições serem capazes de normalizar, estabelecer regras e orientar aos conflitos e rivalidades que perpassam a vida social. Podemos relacionar os apontamentos com a criação das políticas públicas que auxiliam para diminuição das reproduções das desigualdades sociais, dentre elas a de cor, nas instituições de ensino superior. 
Almeida (2019) acrescenta que são nas regras institucionais que os indivíduos se tornam sujeitos. Para além a sociedade, como grupo, não se caracteriza homogêneo devido as contradições, antagonismos e inserido aos conflitos, temos as raciais que também compõem as instituições concebendo o racismo institucional que evidencia a desigualdade racial. Assim, na questão do racismo institucional os parâmetros discriminatórios utilizados se baseiam na raça e servem para preservar a dominação do grupo racial no poder, com isso os conjuntos da sociedade, cultura, padrões estéticos e as práticas de poder são determinados de maneira que sejam inexistentes os espaços para se discutir a desigualdade racial.

Logo, se na formação inicial encontramos fragmentos, por meio dos documentos norteadores (Brasil, 2015; Brasil, 2019), que nos apontam a existência de um lapso que favorece a desigualdade social e/ou racismo institucional. Considera-se a formação inicial de professores de Educação Física pode não alcançar sua emancipação e equidade na conclusão do processo. Nessa situação, quando o egresso não está apto a reconhecer as dificuldades socioculturais e educacionais, faz-se importante ações que possibilitem a superação da reprodução das desigualdades de origem social, étnico racial, econômica, cultural, religiosa, política, de gênero, entre outras, dentro de sua trajetória profissional.

Caso tal condição estabelecida nas Diretrizes Curriculares Nacionais (Brasil, 2015; Brasil, 2019) se efetive, de desigualdade social e ético racial, a identidade do professor já se iniciaria profissionalmente com lacunas, decorrentes da instituição, que se perpetua no contexto educacional, expandindo-se para as dimensões sociais e culturais.

\subsection{Formação inicial: a identidade do professor e a identidade negra}

Espera-se que durante a formação inicial de professores sejam possibilitados rabiscos iniciais de uma identidade docente, a partir de um processo que colabore com a reflexão e autorreflexão da atividade docente e seu imaginário social (Flores, 2018; Machado, 2020). Podemos compreender identidade como um "processo de construção do sujeito historicamente situado. A profissão de professor, como as demais, emerge em dado contexto e momento histórico, como resposta a necessidade que estão postas pela sociedade" (Pimenta, 1999). A partir da significação social que se constrói a identidade de professor, considerando seus valores, a maneira como se percebe no mundo, como pondera suas angústias, anseios, sua história de vida e seu cotidiano.

Pimenta (1999), nos acrescenta que a construção da identidade dos futuros professores perpassa por saberes da docência, são eles a experiência, o conhecimento e os saberes pedagógicos. Juntos a identidade se forma devido o diálogo entre os conhecimentos acadêmicos, historicidade quanto sujeito pertencente a sociedade e a permanência em sua realidade profissional, neste caso formação inicial em Educação Física. Ao compreender-se os saberes assimila-se a socialização a qual o professor se insere com toda sua evolução, transformação e história de vida (Tardif, 2002).

A identidade de professor se suaviza em sua elaboração devido ao seu processo priorizar a construção do humano, que se dá pela mediação do professor acerca das informações para que se alcance o conhecimento, consequentemente a consciência material, social e existencial da humanidade (Costa et al. 2020; Conceição, Quinelatto 2021). Dentre as habilidades da identidade do professor a humanização deve ser priorizada, pois a educação se caracteriza como um processo humanístico, possibilitando aos alunos se fazerem perceber seres responsáveis pelas ações da/na sociedade.

O professor deve-se apresentar ao cenário escolar junto dos estudantes como uma pessoa completa, que possui emoções, linguagem e se relaciona consigo e com o outro (Tardif, 2002). A partir da conjuntura e meios que auxiliam a construção da identidade do professor, características existenciais, sociais e humanísticas, podemos perceber que o ato de ensinar, apreendido durante o processo de formação inicial de professores, dialoga diretamente com a organização social, à medida que a instituição vai se posicionando com suas regras e normas que definem os papéis e posições desse professor em formação. 
A institucionalização se evidencia, a medida em que posiciona a realidade social e coletiva, com suas diretrizes e categorias, e faz os indivíduos se compreenderem como profissionais que são chamados a desempenharem tais normas no tocante de sua ocupação. Esse processo de formação inicial de professores de Educação Física, para além de auxiliar a construção da identidade do professor coincide em assistir os estudantes em seu processo de construção de identidade (Flores, 2019).

Se tratando da construção identitária em sua multiplicidade há de se considerar nesses constructos o processo da identidade negra. Gomes (2003) relaciona o processo identitário negro com uma construção gradativa, que envolve causas e efeitos com inúmeras variáveis. Resultando a percepção da identidade negra como uma construção social, plural e histórica, pois abarca o olhar de um grupo sobre si mesmo considerando sua diversidade étnico racial a partir da relação com o outro.

As identidades se caracterizam a partir dos sujeitos sociais, por meio da percepção de que se relaciona com a cultura e a história, instituições e agrupamentos sociais. A construção desta identidade negra se compõe por meio de processos densos, plurais e uma interlocução com o ambiente escolar que se caracteriza como auxiliador no direcionamento da formação humana, identitária, emancipatória e motora, entre outros (Anversa, 2017; Mota et al. 2021).

Recapitulando o processo de formação de professores em Educação Física e todos os conteúdos que aborda como ginástica, dança, lutas, jogos e brincadeiras e esportes com a possibilidade de formação reflexiva, que se adianta da perspectiva biologicista, os professores em formação devem se perceber quanto profissionais que trabalharão o seu próprio corpo cotidianamente. Assim, ao expor-se os estudantes captam o físico e o mental daquele se apresenta diante deles, porém há uma troca devido o professor não lidar somente com o seu corpo, mas também com o de seus alunos. Nesse processo se destaca os opostos que se conectam pelos sentidos, por meio do toque, da visão e escuta (Gomes, 2003; Oliveira, 2021).

Considera-se a formação inicial de professores de Educação Física com disciplinas, atividades, estágios, e programas de fomento e incentivo a formação para a docência precisa promover uma articulação entre universidade-escola que possibilite a ampliação da relação com a comunidade escolar, com foco na interação com os constructos que integram a profissão, e que oportunizem a aprendizagem acerca das relações étnico raciais, a partir do cenário em que o futuro professor direcionará sua ação didático pedagógica centrada nas diretrizes sócio-políticas estabelecidas pelos documentos mandatórios que legalizam e legitimam a educação básica brasileira, a exemplo da atual Base Nacional Comum Curricular (Brasil, 2018b), em que o professor carece romper com as estruturas postas buscando para além dos documentos na sua prática cotidiana contribuir para a redução das desigualdades sociais, a multiculturalidade, as diferenças ressaltadas pela cor, como nos apontam as últimas Diretrizes Curriculares Nacionais para a formação de professores (Brasil, 2019).

\section{Metodologia}

Este estudo trata-se de uma pesquisa qualitativa, caracterizada como sendo revisão integrativa, a qual se configura como uma síntese de conhecimento dos estudos produzidos acerca da temática escolhida e discussão de ideias disseminadas por meio da produção acadêmica sobre um assunto em um período determinado pelo pesquisador (Mendes, Silveira, Galvão, 2019).

A revisão integrativa, percorrendo seus procedimentos (Galvão, Mendes, Silveira, 2010) foi construída a partir de três etapas. Na primeira, estabeleceu-se a questão problema do estudo e os bancos de dados que seriam utilizados para o levantamento, Periódicos Capes, Scielo, Lilacs e Biblioteca Digital Brasileira de Teses e Dissertações com os descritores "formação de professores", "relações étnico raciais", "étnico racial”, "formação", "Lei 10.639/03" e "educação física", juntamente com o operador booleano "AND” entre os termos. Como critérios de inclusão estabelecemos que os artigos aceitos deveriam estar no idioma português, publicados entre os anos de 2015 e 2020, e abordar o assunto referente a formação de professores em Educação Física e relações étnico raciais. 
$\mathrm{Na}$ segunda etapa ocorreu a seleção do material selecionado, a partir da leitura do título e do resumo dos artigos, excluindo os artigos com publicação duplicada, artigo de opinião, livros, resenhas, que abordassem outra área ou não se referissem ao processo de formação inicial em educação física e relações étnico racial. O resultado nos concedeu 115 artigos e 38 teses e dissertações. A terceira etapa constituiu-se da identificação dos artigos que contribuíssem para com o objetivo do estudo, a saber: apresentar uma revisão integrativa sobre como a formação de professores possibilita uma educação antirracista e auxilia a construção da identidade do professor e identidade negra dos alunos (Figura 1).

Figura 1. Fluxograma do processo de seleção das fontes.

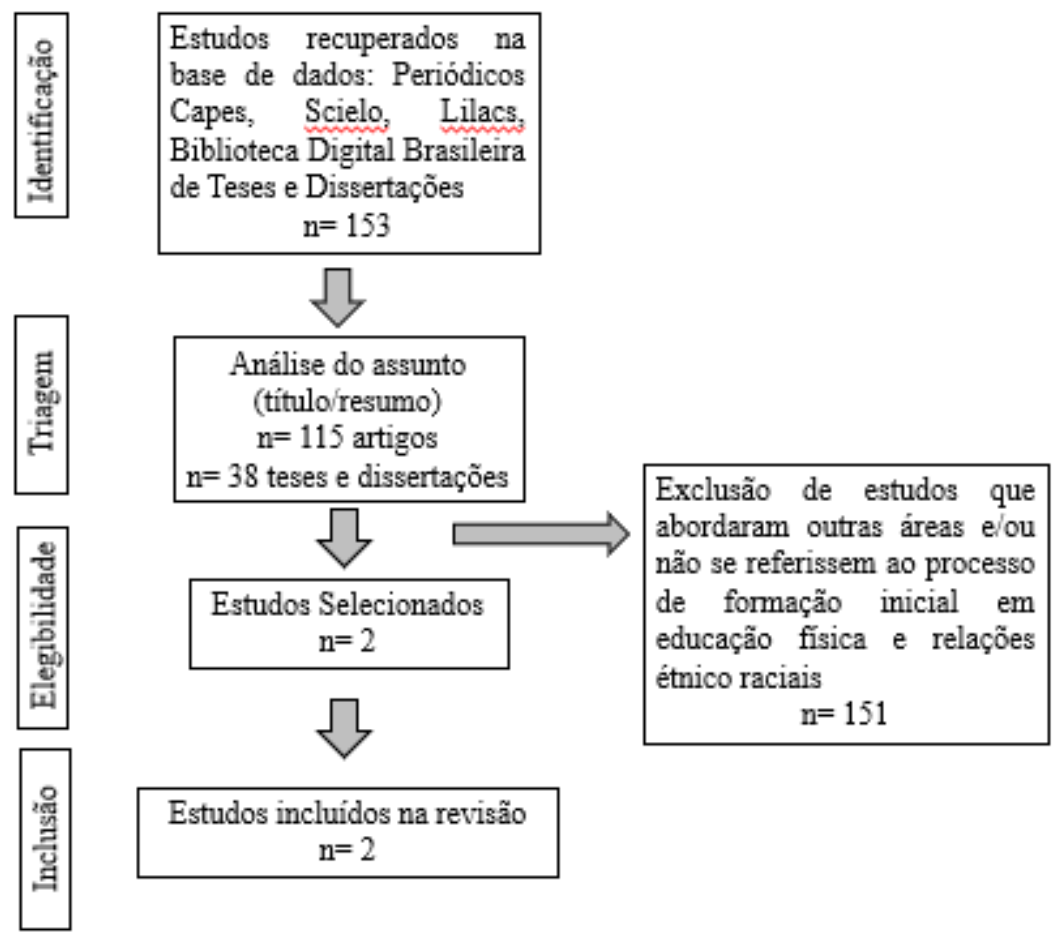

Fonte: Autores.

A partir dos critérios estabelecidos, qualificaram-se ao estudo duas dissertações de mestrado, uma vez que atenderam aos critérios de inclusão, principalmente relacionados a temática abordada (Quadro 1).

Quadro 1 - Características dos artigos selecionados.

\begin{tabular}{|c|c|l|c|}
\hline AUTORES & ANO & \multicolumn{1}{|c|}{ OBJETIVO } & NATUREZA \\
\hline Messias, A. R. & 2019 & $\begin{array}{l}\text { Analisar, tendo como referência a Lei 10.639/03, como a } \\
\text { formação inicial em Educação Física - Licenciatura da } \\
\text { UFSM está integrando as bases necessárias para enfrentar o } \\
\text { desafio da Educação Étnico-Racial e Intercultural para o } \\
\text { espaço escolar. }\end{array}$ & Dissertação \\
\hline Silva, L. D. S. & 2019 & $\begin{array}{l}\text { Analisar a formação inicial de professores nos cursos de } \\
\text { Educação Física escolar e as implicações dessa formação } \\
\text { com relação à Educação das Relações Étnico-Raciais em três } \\
\text { Instituições de Ensino Superior de Mato Grosso do Sul. }\end{array}$ & Dissertação \\
\hline
\end{tabular}

Fonte: Autores. 


\section{Resultados e Discussão}

Os estudos selecionados para a análise da pesquisa referem-se a dissertações resultantes de pesquisas com foco na obtenção da titulação de mestre em Educação Física e Educação respectivamente, no ano de 2019.

A dissertação intitulada "A formação inicial em Educação Física na UFSM: a lei 10.639/03 em uma abordagem intercultural" (Messias, 2019) desenvolvida na região Sul do país e teve como objetivo analisar como a Lei 10.639/03 se articula dentro da formação inicial em Educação Física - Licenciatura da Universidade Federal de Santa Maria, integrando as bases necessárias para enfrentar o desafio da Educação Étnico racial e Intercultural para o espaço escolar. O estudo apontou que a partir da discussão sobre a Lei 10.639/03 há uma necessidade de avançar quanto a aplicabilidade e propostas efetivas que possibilitem a desconstruções de marcadores preconceituosos, além de necessitar de uma formação inicial que vise a articulação comum e o interdisciplinar.

O destaque se faz ao fato da Universidade em questão estabelecer obrigatoriedade da inserção da Lei 10.639/03, porém o curso de Educação Física não adere a mesma ao seu Projeto Pedagógico de Curso, distanciando-se do cumprimento da lei. Para além, destaca-se que o curso apresenta alguns educadores que não reconhecem a importância de tal temática, e com isso podemos retornar a inquietude do presente estudo, ao não se fazer presente na formação inicial de professores de Educação Física, considerando o processo da construção da identidade do futuro professor, a valorização da identidade negra sofre lacunas consideráveis e se direcionam ao reforçamento das desigualdades raciais.

O outro estudo encontrado, intitulado "Educação das relações étnico-raciais nos cursos de licenciatura em Educação Física no Mato Grosso do Sul" (Silva, 2019), foi desenvolvido no Centro-Oeste e teve como objetivo analisar a formação inicial de professores nos cursos de Educação Física escolar e as implicações dessa formação com relação à Educação das Relações Étnico-Raciais em três Instituições de Ensino Superior de Mato Grosso do Sul. O estudo abordou a importância da educação das Relações étnico raciais na formação inicial de professores de Educação Física, a partir das análises dadas pelos acadêmicos nos questionários e da análise das disciplinas ofertadas nos cursos de Educação Física de outras Instituições de Ensino Superior do estado pesquisado.

Silva (2019) reiterou que foi possível considerar que se faz necessário melhorar a estruturação e superar desafios quanto ao conteúdo, uma vez que os cursos têm avançado na contribuição para formação inicial de professores, possibilitando garantir uma educação antirracista que dialoga com as relações étnico raciais.

\section{Considerações Finais}

Com a revisão integrativa realizada, observou-se que, a partir da produção científica das bases de dados analisadas, a formação inicial de professores de Educação Física, sua constituição identitária enquanto professor e a identidade negra não dialogam com a realidade de uma educação antirracista, principalmente no cenário do subcampo científico, considerando a escassez de produções científicas, uma vez que apenas duas pesquisas neste recorte temporal retratam a temática. Os estudos evidenciaram, que a legalidade não se configura como legitimidade.

Quando refletimos acerca da formação inicial de professores de Educação Física pautada pelas relações étnico raciais, estamos visando um processo educativo amplo, que supera unicamente disciplinas, regimentos, normas, provas, conteúdos. Incorporamos uma percepção de que um espaço institucional interfere na constituição da identidade, não somente do professor, mas do estudante negro(a).

Retomando o objetivo do estudo que foi apresentar uma revisão integrativa sobre como a formação de professores possibilita uma educação antirracista e auxilia a construção da identidade do professor e identidade negra dos estudantes (futuros professores), a pesquisa evidenciou que a construção da identidade negra e sua legitimidade nas aulas de Educação Física no processo de formação inicial de professores dessa área de conhecimento e intervenção influencia o olhar direcionado 
ao corpo negro, podendo estigmatizá-lo, discriminá-lo, segregá-lo e até mesmo negá-lo, reproduzindo desta maneira o racismo institucional.

Para tanto, o presente estudo teve como limitação restringir-se em buscar as produções em algumas nas bases de dados acerca da formação inicial de professores de educação física, com período de publicação de 2015 a 2020 . Sugere-se em estudos futuros uma investigação mais ampla, que acrescente formação continuada, de maneira que possibilite compreender se na formação continuada as desenvolturas mudam e há o indicativo de uma educação antirracista, acrescentado da ampliação do recorte temporal de busca.

\section{Referências}

Almeida, S. (2019). Racismo Estrutural. Polén Produção Editorial LTDA.

Anversa, A. L. B. (2017). Estágio curricular e a constituição da identidade profissional do bacharel em educação física.

Anversa, A. L. B., Souza, V. D. F. M. D., Both, J., \& Oliveira, A. A. B. D. (2020). Contributions perceived by students about the curriculum stage in the constitution of professional identity. Journal of Physical Education, 31.

Brasil. (2015). Resolução CNE/CP n. 02/2015 de $1^{\circ}$ de julho de 2015. Diretrizes Curriculares Nacionais para a formação inicial em nível superior. http://portal.mec.gov.br/docman/agosto-2017-pdf/70431-res-cne-cp-002-03072015-pdf/file.

Brasil. (2018a). Resolução CNE/CES n. 6 de dezembro de 2018. Diretrizes Curriculares Nacionais dos Cursos de Graduação em Educação Física. https://www.in.gov.br/materia/-/asset_publisher/Kujrw0TZC2Mb/content/id/55877795/do1-2018-12-19-resolucao-n-6-de-18-de-dezembro-de-2018-55877683

Brasil. (2018b). Ministério da Curricular. http://basenacionalcomum.mec.gov.br/images/BNCC_EI_EF_110518_versaofinal_site.pdf

Brasil (2019). Resolução CNE/CP n. 2 de 20 de dezembro de 2019. Base Nacional Comum para a Formação Inicial de Professores da Educação Básica. http://portal.mec.gov.br/docman/dezembro-2019-pdf/135951-rcp002-19/file

Conceição, W. L. da, \& Quinelatto, R. F. (2021). Lives intertwined by social invisibility: the formation of the teaching identity in the context of socioeducation. Research, Society and Development, 10(8), e37110817361.

Costa, L. C. A. D., Passos, P. C. B., Souza, V. D. F. M. D., Both, J., \& Fiorese, L. (2020). Os professores apoiam a autonomia dos alunos nas aulas de educação física?. Revista Brasileira de Ciências do Esporte, 42.

Costa, L. C. A da, Resende, R., Souza, V. de F. M de, Flores, P. P., Anversa, A. L. B., Contessoto, L. C., \& Nascimento, JV do. (2020). O Modelo de Educação Desportiva como possibilidade de formação: uma experiência na formação inicial em Educação Física. Pesquisa, Sociedade $e$ Desenvolvimento , $9(8)$, e174985556.

da Costa Borim, M. L., da Rocha Romero, F. F., de Queiroz, L. C., Solera, B., Flores, P. P., Ferreira, L., ... \& de Souza, V. D. F. M. (2020). Construção da identidade profissional do professor de educação física na perspectiva do preceptor da residência pedagógica. Brazilian Journal of Development, 6(3), 1430614317.

Silva, T. M. G., de Almeida Junior, D. M., \& Dias, R. F. (2020). Como preparar um professor para "ser" inclusivo: reflexões sobre a formação docente. Research, Society and Development, 9(10), e799106872-e799106872.

Silva Júnior, A. P., Bisconsini, C. R., Flores, P. P., Anversa, A. L. B., \& de Oliveira, A. A. B. (2019). As implicações da configuração interdependente entre estagiários e professores supervisores no estágio curricular supervisionado em Educação Física. Motrivivência, 31(60), 01-23.

Lima Monteiro, J. H., de Queiroz, L. C., Anversa, A. L. B., \& de Souza, V. D. F. M. (2020). O Programa Residência Pedagógica: dialética entre a teoria e a prática. HOLOS, 3, 1-12.

Flores, P. P. (2018). O processo de identização docente durante o estágio curricular supervisionado: em jogo no campo da Educação Física (Doctoral dissertation, Tese de Doutorado, Programa de Pós Graduação em Educação Física, Departamento de Educação Física, Universidade Estadual de Maringá. Maringá, Brasil).

Flores, P. P., Oliveira, A. A. B. D., Martins, R. G. D. L., Both, J., \& Krug, H. N. (2019). The constitution of teacher identification of a first degree in physical education in the perspective of its students. Journal of Physical Education, 30.

Garcia, C. M. (2005). Formação de professores: para uma mudança educativa. Porto, Portugual: Porto Editora.

Galvão, C. M., Mendes, K. D. S., \& Silveira, R. C. C. P. (2010). Revisão integrativa: método de revisão para sintetizar as evidências disponíveis na literatura. Brevidelli MM, Sertório SCM. Trabalho de conclusão de curso: guia prático para docentes e alunos da área da saúde. São Paulo: Iátrica, $105-26$.

Gomes, N. L. (2003). Educação, identidade negra e formação de professores/as: um olhar sobre o corpo negro e o cabelo crespo. Educação e pesquisa, 29(1), 167-182.

Hirsch, J. (1990). Forma política, instituições políticas e Estado-I. Economies et Societés, (12), 139.

Machado, L. R., Sacramento, A. M. dos S., \& Lobato, G. de A. B. (2020). Training, identity and inclusive practices of children's education teachers. Research, 
Research, Society and Development, v. 11, n. 3, e35311326567, 2022

(CC BY 4.0) | ISSN 2525-3409 | DOI: http://dx.doi.org/10.33448/rsd-v11i3.26567

Society and Development, 9(10), e8589109197.

Mendes, K. D. S., Silveira, R. C. D. C. P., \& Galvão, C. M. (2019). Uso de gerenciador de referências bibliográficas na seleção dos estudos primários em revisão integrativa. Texto \& Contexto-Enfermagem, 28.

Messias, A. R. (2019). A formação inicial em educação física na UFSM: a lei 10.639/03 em uma abordagem intercultural.

Mota, P. A. T.., Barbosa, T., Dublante, C. A. S.., Ribeiro, D. dos R.., Silveira, F. M. da., Almada, F. de A. de C.., \& Silva, I. M. de O.. (2021). The challenge of teacher education. Research, Society and Development, 10(12), e193101220238.

Oliveira, M. N. de., Cely, E., Simões, G., \& Polati, C. (2021). Afro-Brazilian culture in Physical Education at school: expectation or reality in teaching practice?. Research, Society and Development, 10(13), e396101321438.

Pimenta, S. G. (1999). Formação de professores: identidade e saberes da docência. Saberes pedagógicos e atividade docente. São Paulo: Cortez, 4.

Ramalho, M. C., Caraçato, Y. M. da S., Queiroz, L. C. de, Romero, F. F. da R., Solera, B., Anversa, A. L. B., Flores, P. P., Oliveira, A. A. B. de, \& Souza, V. de F. M. de. (2021). Approaches to the school floor in the experience of Physical Education pibidians. Research, Society and Development, 10(4), e2910413789.

Silva, L. D. S. (2019). Educação das relações étnico-raciais nos cursos de licenciatura em educação física no Mato Grosso do Sul.

Tardif, M. (2012). Saberes docentes e formação profissional. Editora Vozes Limitada. 